\title{
Premorbid development in twins with schizophrenia
} MM Picchioni*1, T Toulopoulou' ${ }^{1}$, A Regojo ${ }^{1}$, F Rijsdijk², S Landau ${ }^{3}, \mathrm{M}$ $\mathrm{H} \mathrm{Hall}^{1}$, S McIntyre ${ }^{1}$ and RM Murray ${ }^{1}$

Address: ${ }^{1}$ Kings College London, Institute of Psychiatry, Division of Psychological Medicine, London, UK, ${ }^{2}$ Kings College London, Institute of Psychiatry, Social, Genetic and Developmental Psychiatry Centre, London, UK and ${ }^{3}$ Kings College London, Institute of Psychiatry, Department of Biostatistics and Computing, London, UK

* Corresponding author

from International Society on Brain and Behaviour: 3rd International Congress on Brain and Behaviour

Thessaloniki, Greece. 28 November - 2 December 2007

Published: 17 April 2008

Annals of General Psychiatry 2008, 7(SuppI I):S256 doi:10.1 186/1744-859X-7-SI-S256

This abstract is available from: http://www.annals-general-psychiatry.com/content/7/SI/S256

(c) 2008 Picchioni et al.; licensee BioMed Central Ltd.

\section{Background}

Premorbid developmental abnormalities have often been reported in patients with schizophrenia but it is not clear whether these are genetic or environmental in origin.

\section{Materials and methods}

Twin pairs $(n=77)$ varying in their concordance and zygosity for schizophrenia were assessed for premorbid adjustment and personality. We used bivariate genetic model fitting techniques to quantify the genetic relationship between schizophrenia and developmental abnormalities and to estimate the heritability of these traits

\section{Results}

Premorbid deficits in adjustment and personality were associated with schizophrenia. Heritability estimates were greatest for adolescent developmental abnormalities and schizotypal personality traits, while significant genetic and phenotypic correlations for each were detected with schizophrenia.

\section{Conclusions}

Premorbid abnormalities of adjustment and personality are detectable in those who will later develop schizophrenia. These deficits reflect the shared influence of the genetic risk for schizophrenia, and could consequently act as endophenotype markers for the disorder.

\section{Acknowledgements}

Supported by the Wellcome Trust (Fellowship 06497 I to M.M.P.) and the Stanley Medical Research Institute. 